\title{
Decision making in thoracolumbar fractures
}

\author{
Hassan Dashti, Haw Chou Lee*, Eldin E. Karaikovic, Robert W. Gaines Jr \\ Department of Orthopaedic Surgery, University of Missouri-Columbia and Columbia Orthopaedic Group and Columbia Spine Center, \\ Columbia, Missouri, *ENHMG Orthopaedic Surgery, Evanston Northwestern Healthcare, Northwestern University, Chicago, Illinois, \\ USA
}

\section{Introduction}

Thoracolumbar fractures occur from any and all forms of trauma. Twenty percent of them may be associated with neurological deficits. In high energy trauma, up to $5 \%$ of patients will have non-contiguous fractures (i.e. segmental fractures. ${ }^{[1,2]}$ Sixty percent of patients with spinal cord injuries will have associated non-spinal injuries. ${ }^{[3]}$

The management of thoracolumbar fractures continues to evolve. Strong agreements exist in certain aspects of care but significant controversy remains in many other areas. This paper reviews our current diagnostic and therapeutic approach to treating these injuries as of the spring of 2005 .

\section{Evaluation}

Initial assessment of a patient should include the history of an injury from as accurate a source as possible, a thorough physical examination, and an accurate assessment of the patient's neurological status and spinal stability to identify all the associated major injuries that have occurred.

Needs proper wording. Clearly, assessment of neurological status and spinal stability is independent of identification of 'associated injuries'.

Treatment priorities include resuscitation of patient, and treatment of life-threatening injuries before mechanical restoration of the injured osteoligamentous column and preservation or restoration of neurological function.

Every spine surgeon has to answer three fundamental questions when facing a thoracolumbar fracture: First, how to treat a patient (non-operative or operative)? Second, how many segments should one instrument and fuse (short versus long segment operation)? Third, which approach should be used (anterior, posterior or both)? The three fundamental questions are 1. whether to operate, 2. When to operate (emergent, next day, or later), and 3. How to operate (anterior or posterior or combined approach.

The answers to the above questions begin with a complete evaluation.

\section{Patient}

Comprehensive assessment of the patient must be performed. The medical issues that have occurred in the past must be identified. Medically unfit, obese, demented or noncompliant patients have to be identified. Their pre-injury personality characteristics influence treatment choices and the successful use of short segment surgical reconstruction. Medical problems that determine the patient's suitability for surgical reconstruction must be identified and assessed.

Short segment reconstructive options - the most sophisticated reconstruction now available—are more appropriate for physically fit, intelligent, healthy patients who can understand the need for compliance with post-operative recommendations until their fracture heals. Non-compliant patients, patients with past psychological disturbances, drug abusers and alcoholics are especially vulnerable to surgical failures. The inability to co-operate with post-operative bracing makes long segment instrumentation and fusion the best reconstructive option for people who cannot be trusted to understand the importance of post-operative bracing.

\section{Clinical assessment}

Spine fractures usually result from blunt injuries, which can cause other long bones fractures too. A high index of suspicion must be maintained with palpation of all.joints and bones during examination. Full neurological examination (sensation, motor, anal tone, [Mention about signs of sacral sparing in complete paraplegia] etc) should be done and documented repeatedly to look for and pick up neurological deficits and deterioration.

The patient's spine must be palpated using log roll to look for tenderness, swelling, haematoma, gibbus or step off. These can indicate the existence of fracture translation. [The purpose for palpation of the spine after log roll is to look for evidence of posterior column injuiry, like wide gap between the spinous process, hematoma, ecchymoses etc] A seat belt bruise, facial fractures, pelvic hematoma and calcaneus fractures can suggest the possible existence of major organ injuries that should be addressed by the trauma and general surgeon first. Resuscitation 
with protection of the spinal column must be instituted simultaneously. (Figures 1 and 2)

Missed injuries are common, especially in obtunded patients. Daily re-evaluation is necessary for all patients, but particularly necessary in patients who present unconscious from head injury. $[1,2]$

\section{Imaging studies}

The first imaging study performed at our institution, for a multiple trauma patient suspected to have a spinal fracture is a CT scan of the relevant areas. The CT scan is quick to perform and particularly useful in the multiply injured or obtunded patient. It allows the trauma and spine surgeon to decide the extent and severity of bony injuries to make decisions regarding general

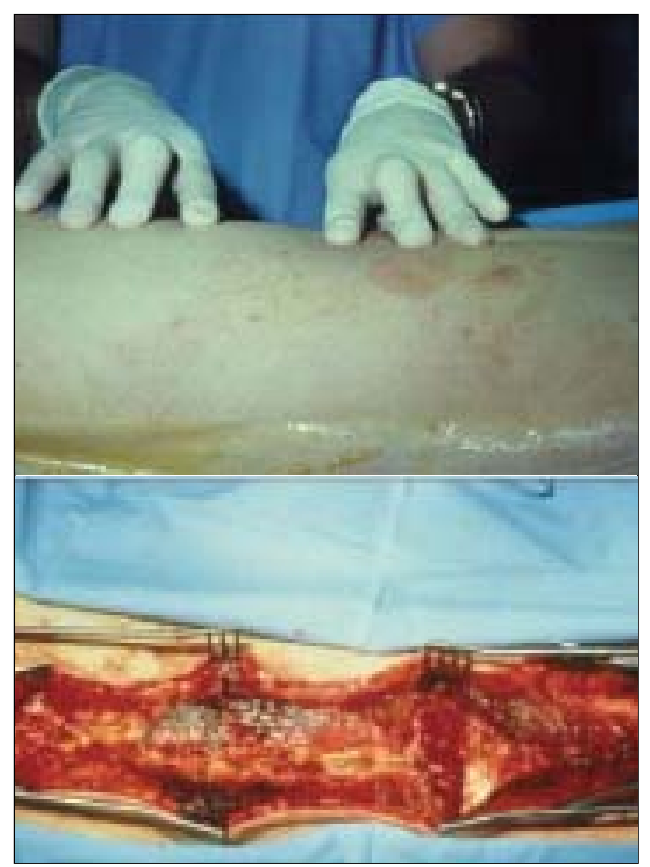

Figure 1: Brusing over the back at the fracture site and fracture hematoma after surgical incision

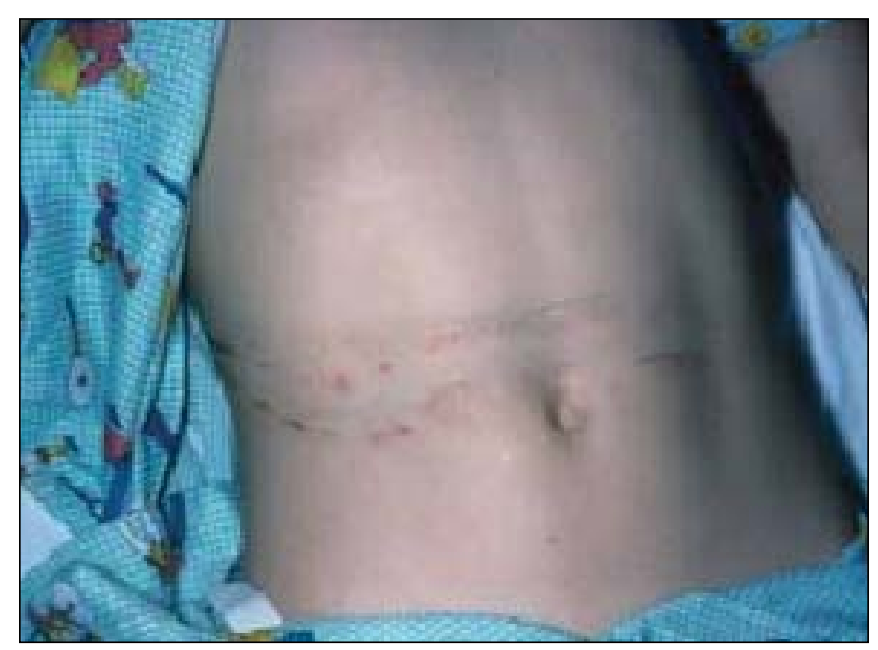

Figure 2: Telltale seatbelt sign of bruising across the abdomen surgical care, as well as spine care, quickly.

Plain radiographs of the spine demonstrate the loss of vertebral height of a broken vertebra, its kyphotic angle and interpedicular distance. [and interspinous distance in AP and Lateral views and alignment of the spinous process to see rotation of the vertebra] Detailed thin sliced (one millimetre) axial CT scans with sagittal and coronal reconstruction scans, together with $\mathrm{AP}$ / Lat radiographs of the fracture site further delineate the spinal fracture. These two studies evaluated bony spinal anatomy well.

MRI is recommended for patients with neurological injuries to determine the extent of cord or cauda-equina injury, as well as epidural haematoma; soft tissue injuries are also well demonstrated.

These three modalities of imaging provide distinct and complimentary information about the fracture.

The radiographic appearance of the fracture might not be accurate due to its closed reduction, which occurs when the patient is placed on a backboard. However, a careful clinical evaluation (history, mechanism of injury, local swelling, a palpable defect in interspinous ligaments, a neurological deficit) and completed imaging studies (plain radiographs, CT scans, and MRI) can identify all the injuries (facet subluxation, pedicle rotation, malalignment, soft tissue swelling), which guide the surgeon in his assessment of the severity and nature of the injury.

The most important fracture characteristic to identify is the presence or absence of TRANSLATION in antero-posterior or latero-lateral direction eg in the coronal or sagittal plane. Presence of translation in a spine fracture defines that fracture as a FRACTURE DISLOCATION. Grotesque disruptions are visualised easily. However, subtle translational displacement of the spinal column also indicates disruption of the anterior longitudinal ligament (ALL), posterior longitudinal ligament (PLL), capsular ligaments, ligamentum flavum and disc disruption (Figure 3) — the very same structural injuries that characterize spinal injures with grotesque translation. Whether translational displacement is mild, moderate or severe, it is the
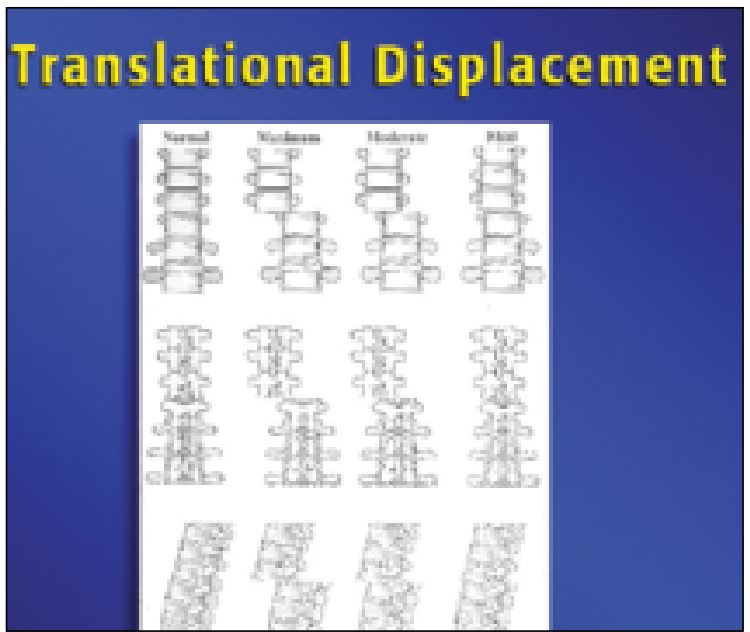

Figure 3: Anterior, posterior and lateral views of translational displacement of the spine.The drawings on the left represent an intact spine, followed by drawings of translation from gross to subtle 
very most important structural abnormality, which guides decisions regarding operative stabilization. Any patient with a fracture with translational displacement who is healthy enough to tolerate surgical stabilization should be stabilized.

Translational displacement of the spine is a fracture characteristic seen in patients who have sustained particularly high-energy injuries. The resulting disruptions can be ligamentous, bony or a combination of both. There is a high rate of intraabdominal injury $(45 \%)$ with this injury pattern, ${ }^{[20]}$ and neurological injury of $10-15 \% .^{[21]}$

Injuries with translational displacement are associated with the highest rate of neurologic injury, and should usually receive surgical stabilization to optimize both spinal alignment and to preserve neurologic function.

\section{Fracture classification/description}

[This section need major rewrite up. Classification is the backbone of decision making. Surgical Anatomy of Holdsworth two column and Denis three column may be described. Please base the major classification system either on Magerl ABC classification or conventional Denis classification system. Loadsharing classification should only be used as a complement to the one of the above, since it is applicable for assessment of the degree of anterior column comminution and the need for anterior column reconstruction with structural graft/cage. It does not identify the severe unstable injuries like distraction injuries (e.g, Magerl Type B, discoligamentous injury, or Magerl Type C, three column rotational / translational injuries with minimal vertebral body comminution]

Holdsworth, ${ }^{[4]}$ Denis $^{[5,6]}$ Magerl $\mathrm{AO}^{[8]}$ and Load-Sharing ${ }^{[14,15]}$ classifications classify spinal fractures using anatomical and mechanistic principles. They describe a static view of spinal displacement.

The Load Sharing Classification ${ }^{[14,15]}$ was developed after recognition and confirmation in the literature that, by preoperatively quantifying the comminution of the most injured vertebral body, one could predict, with great accuracy, the occurrence of a postoperative loss of reduction with or without pedicle screw fracture for spine firactures treated with short segment posterior instrumentation and fusion (Figure 4a, 4b,4 c).

In this classification, the degree of vertebral body comminution, apposition of the fracture fragments at the fracture site and kyphosis correction were assessed by the preoperative plain Xrays, and sagittal and axial CT scans. Each factor is graded in severity and awarded 1 point for mild, 2 points for moderate and 3 points for severe. Therefore, a total point score - for any fracture-regardless of mechanism, can be created, from 3 to 9 points.

Using this system one can predict uniformly successful bony healing of posterior short segment; pedicle screw-based fixation for fractures with lesser comminution-Load-Sharing classification score of 6 or less. Fractures with Load-Sharing classification scores of 7,8 or 9 - the more comminuted injuries-

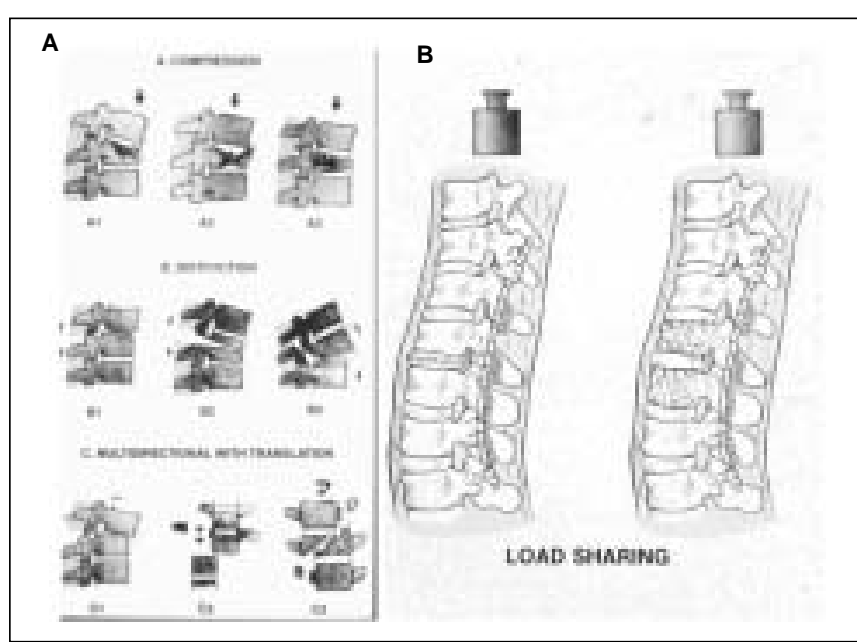

Figure 4a \& 4b: AO Magerl classification and load sharing principle

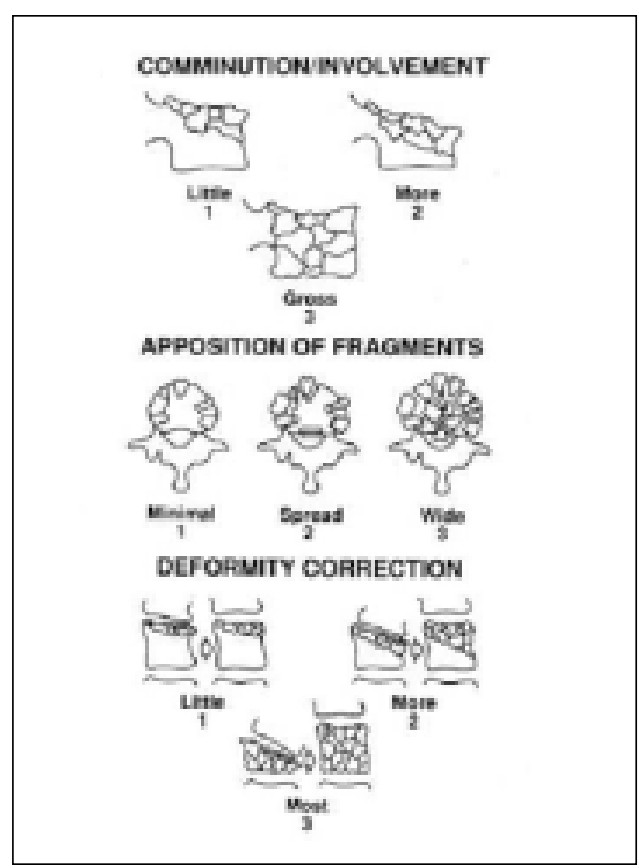

Figure 4c: Load sharing classification

must be reconstructed using short segment anterior strut grafting and anterior instrumentation when the patient is suitable for short segment reconstruction. ${ }^{[14,15]}$

The Load Sharing classification is not a mechanistic classification and does not take into account the condition of the ligaments. The classification simply quantifies how much "bone damage" has occurred in the area of the injury and what has to be repaired by the surgeon.

The point total, itself, does not indicate whether to operate or not, since the ligamentous structures are not considered and the presence or absence of translational displacement is not determined. The presence of translation must be determined separately from the determination of the point total.

However, classifying fractures in this way characterizes the loadtransfer across the injured vertebrae themselves, which lie 
underneath the spinal implants that are used to stabilize the fracture. It is particularly useful in determining when to use short segment posterior pedicle screw based reconstruction and when to avoid this particular approach, in favour of anterior short segment reconstruction.

We use the Load Sharing Classification as our principal way to classify fractures since it leads, more directly than the other classifications, to modern surgical treatment. Aligizakis et al ${ }^{[16]}$ in a prospective study found it to be simple and reliable in predicting the outcome of conservatively treated patients with isolated thoracolumbar fractures and no neurological injury. Dai et al ${ }^{[17]}$ have demonstrated the high inter and intra-observer reliability of the classification.

While other classifications attempt to deduce the "mechanism" of fracture creation, none of them has proven that their deductions are correct, and none of them leads as directly to treatment considerations as the Load Sharing Classification does.

\section{Neurological status}

While rare, one true indication for surgical intervention is the presence of progressive neurological deterioration in the presence of spinal cord compression. ${ }^{[2]}$ when direct spinal canal decompression is promptly performed in such an injury, neurological recovery has been observed. ${ }^{[24-26]}$ Excellent spinal canal decompression can be achieved by either a posterolateral, transpedicular, or an anterior approach. ${ }^{[18,37]}$ Posterior laminectomy decompression alone has been shown not to decompress a spinal fracture adequately. ${ }^{[18,37]}$ Inadequate decompression of the spinal canal can result in ongoing radicular symptoms or development of late myelopathy. ${ }^{[24,26]}$

In the presence of a non-progressive neurological deficit the evidence supporting surgical decompression is conflicting. Several studies have failed to show an advantage for the surgical intervention over non-surgical treatment. ${ }^{[20-24]}$ We feel that canal compromise in the absence of a neurological deficit is not an indication for surgery, since canal remodelling can occur with time,in patients whose fractures are surgically reduced and stabilized. ${ }^{[25-31]}$ Dai et al ${ }^{[33]}$ found the degree of spinal canal stenosis was similar in those treated nonoperatively as compared to operatively. In a comprehensive review of the literature, Boerger et $\mathrm{al}^{[29]}$ failed to find support for canal clearance. Mohanty et al ${ }^{[42]}$ found in a prospective study that there was no correlation between neurological recovery and the degree of canal compromise. These studies go on to recommend nonoperative treatment for patients with none or mild neurological impairment. Boerger et $\mathrm{al}^{[29]}$ go as far as to state that in the absence of instability any canal clearance by surgical intervention would be causing a patient a disservice.

There is no role of isolated laminectomy for decompression of thoracolumbar fractures, since laminectomy disrupts the posterior elements contributing to further instability. In the absence of stabilisation, laminectomy results in the development of iatrogenic kyphosis, and it has no effect on spinal occlusion up to $35 \% .^{[37-40]}$
It may also result in lower rates of neurological recovery as compared to anterior decompression and stabilisation. ${ }^{[41]}$

\section{Surgeon}

Surgeon's expertise and available resources also have an important impact on types of intervention undertaken. In certain areas of the world where prolonged hospital care with bedrest is economically unviable, a surgical route will be undertaken to reduce costs for an injury that would easily be treated non-operatively.

If well trained surgeons and hospital-based equipment is not available, then non-operative treatment, or referral to a properly equipped surgical center should occur.

\section{Operative vs non-operative treatment options}

The aim of treatment is restoration of function of the patient by creating a healing environment to allow a stable pain free spinal column, with the minimal risk to the patient. The advantage of non-operative method of treatment has been to avoid operative morbidity, such as infection, iatrogenic neurological injury, pseudarthrosis, implant failure and complications of anaesthesia.

Again, the factors we consider in choosing the type of surgical treatment are:

1. Severity and location of spinal ligament injuries (clinical and imaging)

2. Quantify the fracture comminution using the Load Sharing Classification

3. Patient factors (health, age, weight, premorbid, associated injuries)

Following this, good judgement regarding the risk/benefit of operative vs non-operative care can be made.

If, after evaluating the patient, the fracture pattern and patient's neurological status, the decision leans towards nonoperative treatment, appropriate braces are chosen. Patients should be taught how to wear orthosis and counselled on their restrictions until bony healing takes place.

Many studies have failed to show the functional benefit between operative and nonoperative treatment of stable injuries. ${ }^{[43-45]}$ Conservative measures have shown to yield adequate results ${ }^{[48]}$ even in the presence of selective three column spine fractures, and with early mobilisation. ${ }^{[49]}$ Chow et $\mathrm{al}^{[50]}$ showed that with careful bracing or hyperextension bracing in patients with posterior ligamentous injuries yielded good results. It is imperative that nonoperative treatment should be closely monitored as there is the potential for progression of deformity and development of neurological deficit. ${ }^{\text {[9-51] }}$

There is no question that a multiple injured patient is easier managed after spinal stabilisation. Also, progressive neurological deficit indicates emergent decompression and stabilisation.

The mechanically unstable spine with translational displacement needs surgery. In severely injured patients early intervention, less than 72 hours, results in fewer complications, shorter hospital stay and reduced requirement for ventilation. ${ }^{[52,53]}$ There is considerable controversy with regards to the timing of surgery in 
the presence of neurological injury. Animal studies that showed early intervention had better results have failed to be proven in clinical setting in humans. Studies relating to timing of surgical intervention are few, and they relate to cervical cord injuries.

We feel that the timing of surgery dependents on hospital logistical and resources issues. A skilled operative and anesthesia team ready to perform the surgery is more important than any patient-related variable, except occurrence of neurological deterioration. If the anterior approach is chosen it is beneficial to wait 3-4 days after the injury which allows the period of hyperaemia at the fracture site to resolve which decreases bleeding during the procedure.

\section{Length of fusion: Short vs long segment fusion}

Long segment fusion (instrument two or more levels above and below a fractured vertebra) is stronger and stiffer (higher ultimate failure strength) than Short Segment fixation (instrumentation one level above and below a fractured vertebra); however it sacrifices spinal motion.

The location of the fracture can influence the surgeon's choice of fusion. A long fusion in the upper and middle thoracic spine does not reduce patient's spinal mobility and function very much. However, the thoracolumbar and lumbar spines are functionally very important. Preservation of mobility in these segments of the spinal column is fundamental — particularly in manual workers whose jobs require increase demands on the spine. (Figure 5)

Our experience with short segment pedicle screw-based fixation has been superb over the past 20 years for low point total ( 6 points or less) spinal fractures without translation. When the pedicles are large enough to accept pedicle screws, we never use hooks and/or wires. While out of bed the patient must wear a brace, for $6-8$ weeks until the fusion consolidates.

Anterior short segment instrumentation and fusion is used for patients with point totals of 7,8 or 9 who have no translational displacement, e.g. a fracture dislocation. Our results after 20 years experience are excellent with this approach, if the patient is willing to wear an orthosis for 6 - 8 weeks following the reconstruction.

Only fracture-dislocations (injuries with translation) are treated with posterior long segment instrumentation and/or anterior procedures to reconstruct very severely comminuted vertebral bodies at the apex of these injuries. Over $25 \%$ of these patients have severe neurological injuries — many of which only partially recover.

\section{Surgical approaches}

Once a decision for surgery is made, the surgeon has to decide how to approach the injury-anteriorly, posteriorly or both approaches. Decompression in presence of neurological deficit can be done effectively either anteriorly (corpectomy) or posteriorly (transpedicular).

We utilise Short Segment fixation for young healthy people with isolated spinal injuries. Posterior fixation is used for low point total fractures ( 6 or less) and anterior fixation only for high point injuries ( 7 or more). Injuries with translational displacement are treated with posterior fixation only in low point injuries $(<7)$ and a posterior followed by anterior approach for high point injuries ( 7 or more). (Figures $6 \mathrm{a}, 6 \mathrm{~b}$ )

Load sharing between the implant and host bone is a fundamental principle that allows bone healing and prevents implant failure. ${ }^{[54]}$ If highly comminuted and displaced vertebral fractures are treated with posterior instrumentation only, pedicle screw fracture commonly occurs, since the load-sharing across the fracture site itself is poor. ${ }^{[14,15]}$

When a single vertebral body is highly comminuted, anterior reconstruction of the spinal column and anterior instrumentation is superior to posterior fixation. ${ }^{[55-59]}$ While we used a full-thickness autologous iliac strut graft to reconstruct the spinal column for 15 years with excellent results, we now prefer a modular and stackable carbon cage spacer filled with autograft from the vertebrectomy and excised rib, with the same type of dual rod/ screw implants. (Figure 7) Use of the modular cage avoids the large iliac crest donor site pain.

Regardless of the fixation system used, we must be careful not to over distract the fracture site. The normal sagittal and coronal spinal alignment must be restored, with or without fully correcting the vertebral height. Overzealous distraction using a principle of ligamentotaxis creates a gap (empty space) at the fracture site which further decreases the load sharing of the axial forces between the implants and the fractured body, and should be avoided.

Failure of the posterior systems occurs by breakage, bending or loosening in patients. The critical period for developing instrumentation problems appears to be 6 months. ${ }^{[15,55,58,61]}$ Compared to an intact spine, posterior instrumentation has $76 \%$ of intact spine stiffness, a posterior system with an anterior strut is $3 \%$ stiffer and anterior instrumentation with anterior strut graft is $15 \%$ stiffer than the intact spine. ${ }^{[64]}$ Loss of correction on the anterior systems has shown to be 1-4 degrees, ${ }^{[15 ; 65]}$ as compared to 3-12 degrees for the posterior systems. Instrumentation failure rates for the posterior systems range from $9-54 \%$, whereas it was $4-11 \%$ for the anterior systems. ${ }^{[6]}$

\section{Post- traumatic kyphosis}

Post-traumatic kyphosis is a clinical and radiological condition, which results from healing without surgical internal fixation of fractures with severe comminution and translational displacement, or following a failure after operative stabilization. It can develop due to failure to recognise or under-estimation of translational injuries, poor bone quality, inadequate spinal bracing or follow up, or errors in surgical technique or spinal healing. It can be mild, moderate or very severe.

Patients can present with mechanical or neurological symptoms. Mechanical symptoms include pain, fatigue, instability and progression of kyphosis. Neurological symptoms include development of a new or progression of with a fracture already established neurological deficit. Back pain is the most common presenting feature and indication for intervention. - The pain is 


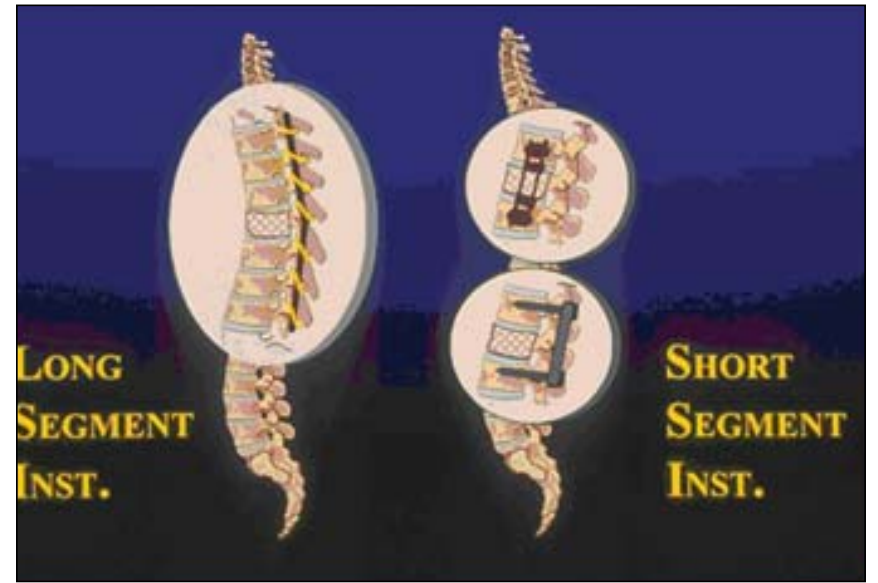

Figure 5: Short vs long segment instrumentation

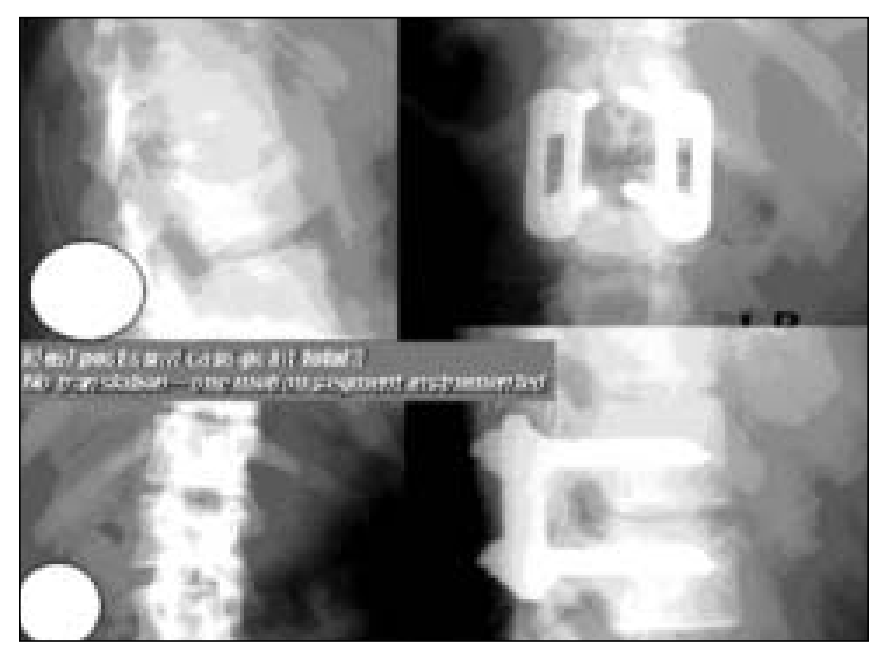

Figure 6a: Posterior fixation only in low point injuries $(<7)$

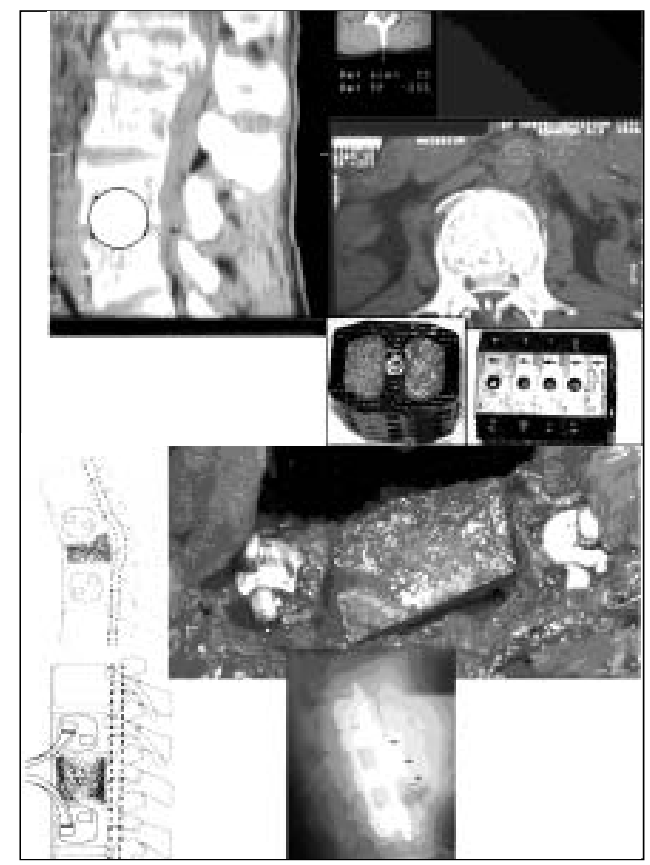

Figure 6b: Anterior fixation only in high point injuries (7 or more) using strut grafts or carbon cages with neutralising dual rod system

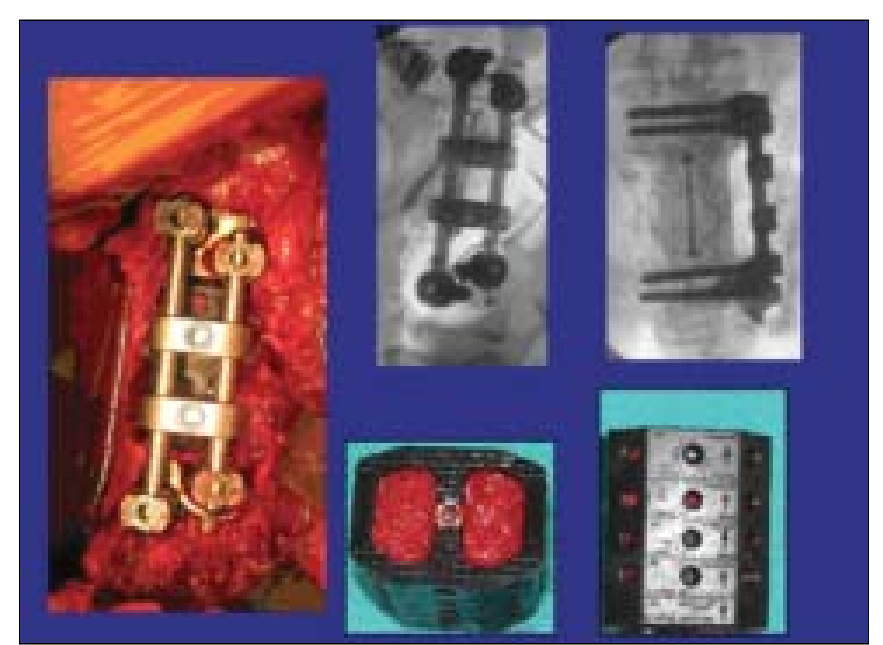

Figure 7: Anterior system with carbon cages for load sharing and bicortical purchase vertebrae screws with dual rod/cross link for neutralizing

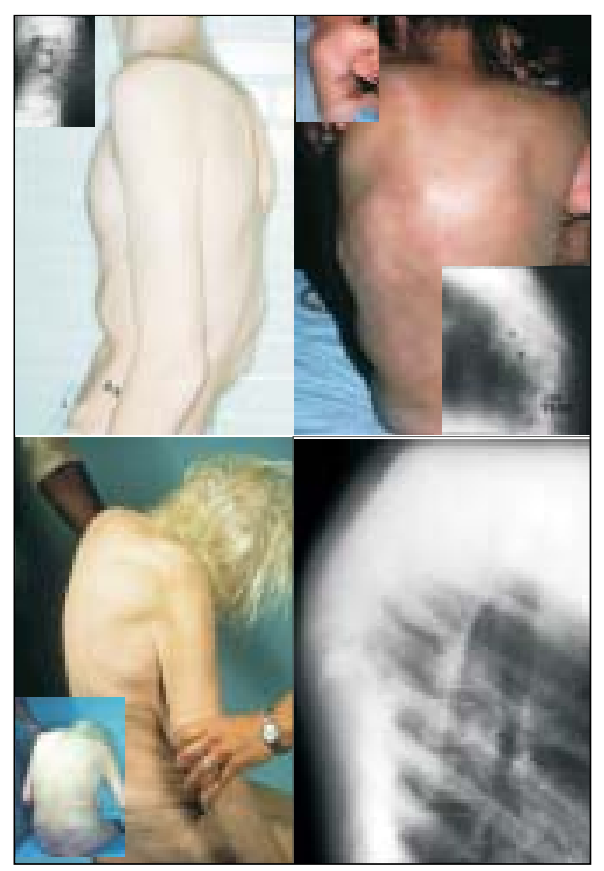

Figure 8: Examples of post traumatic kyphosis

mechanical in nature and localised at the apex of the deformity. Prolonged standing, bending, lifting and twisting, aggravates it. It is often difficult to pinpoint the aetiology of the pain, but segmental instability, muscle fatigue, degenerative changes and stresses to the posterior tensile structures have been implicated. Spinal cord or nerve root compression commonly occurs particularly in moderate or severe cases (Figure 8).

While surgical management of these very complicated and disabling problems can occur, prevention of post-traumatic kyphosis is much simpler and less expensive than its treatment.

The application of proper patient assessment, radiological study assessment, commonplace use of the Load Sharing Classification and use of Short Segment posterior instrumentation of fractures with a point total injuries of 6 or less and short segment anterior 
reconstruction for fractures with point totals over 7 has eliminated severe posttraumatic kyphosis from our practice. [Load-sharing classification is applicable for assessment of fresh fractures and not for late posttraumatic kyphotic deformity.]

In measurements of kyphosis there are great interobserver variations. We prefer to measure kyphosis from the superior end plate of the vertebra above to the inferior vertebrae of the vertebrae below the fractured one. ${ }^{[57,69]}$ Though there is literature ${ }^{[60,67]}$ to show that a kyphosis of greater than 30 degrees is statistically associated with an increased incidence of back pain, it has also been shown that there is no relationship between a degree of kyphosis and back pain or poor functional outcome. ${ }^{[3-52]} \mathrm{N}_{0}$ correlation has been found between wedge angle and functional outcome. ${ }^{[68]}$ An absolute indication for intervention is new or progressive neurological deficit. Other indications for intervention are pain uncontrolled by nonoperative measures, progression of kyphosis and cosmesis.

Goal of surgical intervention is pain reduction, improvement or prevention of progression of neurological deficit, correction of deformity and stability.

Most posttraumatic kyphotic deformities are fixed and isolated posterior fixation leads to high failure and pseudarthrosis rates. With posterior stabilisation the moment arm is great resulting in high tensile strength on the implant and bone graft. We rarely use the posterior alone correction for kyphosis secondary to thoracic compression fractures over multiple levels. Pedicle subtraction osteotomy is more appropriate to gain correction for severe deformities.

Anterior fusions are placed under compression and improved circumstances for fusion. Isolated anterior decompression and fusion can be utilised constructively. ${ }^{[70]}$ Kaneda ${ }^{[56]}$ has shown good results with anterior decompression, correction of deformity and stabilisation.

With curves greater than $60^{\circ}$ the kyphosis, there is inherent posterior instability. Pain relief can occasionally be achieved by stabilization and fusion rather than deformity correction. ${ }^{[71]}$ This is best achieved by combined anterior/posterior stabilisation and fusion. Malcolm at $\mathrm{el}^{[60]}$ reviewed 48 patients and concluded that anterior and posterior reconstruction had no failures and fusions were successful, but with isolated anterior correction there was a $50 \%$ failure rate. Complete pain relief was achieved in only $67 \%$ of cases. Roberson and Whitesides found a similarly good result with anterior/posterior reconstruction. ${ }^{[67]}$

\section{Conclusion}

Adequate preoperative evaluation of thoracolumbar fractures can optimise their care. Proper assessment with good management helps to return many of such victims to productive lives earlier. Thorough understanding of biomechanies, clarity of imaging and application of principles of load sharing, are the grounds for nonoperative versus surgical treatments. This can prevent development of post-traumatic kyphosis or scoliosis.
A treatment plan is never based only on assessment of the anatomy of the fracture. Patient assessment is fundamental in choosing the treatment options of thoracolumbar spinal injuries. Only after a thorough patient evaluation of patient's social, educational background, age, occupation, spinal level of the injury and patient's expectations do we make an individualised treatment plan.

\section{References}

1. Kewalramani LS, Taylor RG. Multiple Non-Contiguous Injuries to the Spine. Acta Orthop Scand 1976;47:52-8.

2. Henderson RL, Reid DC, Saboe LA. Multiple Noncontiguous Spine Fractures. Spine 1991;16:128-31.

3. Saboe LA, Reid DC, Davis LA, Warren SA, Grace MG. Spine Trauma and Associated Injuries. .J Trauma 1991;31:43-8.

4. Holdsworth F. Fractures, Dislocations, and Fracture-Dislocations of the Spine. J Bone Joint Surg Am 1970;52:1534-51.

5. Denis F. Spinal Instability As Defined by the Three-Column Spine Concept in Acute Spinal Trauma. Clin Orthop 1984;189:65-76.

6. Denis F. The Three Column Spine and Its Significance in the Classification of Acute Thoracolumbar Spinal Injuries. Spine 1983;8:817-31.

7. Gertzbein SD. Spine Update. Classification of Thoracic and Lumbar Fractures. Spine 1994;19:626-8.

8. Magerl F, Aebi M, Gertzbein SD, Harms J, Nazarian S. A Comprehensive Classification of Thoracic and Lumbar Injuries. Eur Spine J 1994;3:184-201.

9. Panjabi MM, Oxland TR, Kifune M, Arand M, Wen L, Chen A. Validity of the ThreeColumn Theory of Thoracolumbar Fractures. A Biomechanic Investigation. Spine $1995 ; 20: 1122-7$.

10. James KS, Wenger KH, Schlegel.JD, Dunn HK. Biomechanical Evaluation of the Stability of Thoracolumbar Burst Fractures. Spine 1994;19:1731-40.

11. Haher TR, Bergman M, O'Brien M, Felmly W'T, Choueka J, Welin D, et al. The Effect of the Three Columns of the Spine on the Instantaneous Axis of Rotation in Flexion and Extension. Spine 1991;16:S312-8.

12. McAfee PC, Yuan HA, Lasda NA. The Unstable Burst Fracture. Spine 1982;7:36573.

13. Ballock RT, Mackersie R, Abitbol J.J, Cervilla V, Resnick D, Garfin SR. Can Burst Fractures Be Predicted From Plain Radiographs? J Bone Joint Surg Br $1992 ; 74: 147-50$

14. McCormack T, Karaikovic E, Gaines RW. The Load Sharing Classification of Spine Fractures. Spine 1994:19:1741-4.

15. Parker JW, Lane JR, Karaikovic EE, Gaines RW. Successful Short-Segment Instrumentation and Fusion for Thoracolumbar Spine Fractures: a Consecutive 41/2-Year Series. Spine 2000;25:1157-70.

16. Aligizakis A, Katonis P, Stergiopoulos K, Galanakis I, Karabekios S, Hadjipavlou A. Functional Outcome of Burst Fractures of the Thoracolumbar Spine Managed Non-Operatively, With Early Ambulation, Evaluated Using the Load Sharing Classification. Acta Orthop Belg 2002;68:279-87.

17. Dai LY, Jin W.J. Interobserver and Intraobserver Reliability in the Load Sharing Classification of the Assessment of Thoracolumbar Burst Fractures. Spine $2005 ; 30: 354-8$.

18. Been HD, Bouma G.J. Comparison of Two Types of Surgery for Thoraco-Lumbar Burst Fractures: Combined Anterior and Posterior Stabilisation Vs. Posterior Instrumentation Only. Acta Neurochir Wien 1999;141:349-57.

19. Shono Y, McAfee PC, Cunningham BW. Experimental Study of Thoracolumbar Burst Fractures. A Radiographic and Biomechanical Analysis of Anterior and Posterior Instrumentation Systems. Spine 1994;19:1711-22.

20. Anderson PA, Rivara FP, Maier RV, Drake C. The Epidemiology of SeatbeltAssociated Injuries. J Trauma 1991;31:60-7.

21. Gumley G, Taylor TK, Ryan MD. Distraction Fractures of the Lumbar Spine. J Bone Joint Surg Br 1982;64:520-5.

22. Dimar JR, Glassman SD, Raque GH, Zhang YP, Shields CB. The Influence of Spinal Canal Narrowing and Timing of Decompression on Neurologic Recovery After Spinal Cord Contusion in a Rat Model. Spine 1999;24:1623-33.

23. Gertzbein SD. Neurologic Deterioration in Patients With Thoracic and Lumbar Fractures After Admission to the Hospital. Spine 1994;19:1723-5.

24. Bohlman HH, Kirkpatrick JS, Delamarter RB, Leventhal M. Anterior Decompression for Late Pain and Paralysis After Fractures of the Thoracolumbar Spine. Clin Orthop 1994;300:24-9.

25. Maiman DJ, Larson S.J, Benzel EC. Neurological Improvement Associated With Late Decompression of the Thoracolumbar Spinal Cord. Neurosurgery 1984;14:302-7.

26. McAfee PC, Bohlman HH, Yuan HA. Anterior Decompression of Traumatic Thoracolumbar Fractures With Incomplete Neurological Deficit Using a Retroperitoneal Approach. J Bone Joint Surg Am 1985;67:89-104.

27. Gertzbein SD. Scoliosis Research Society. Multicenter Spine Fracture Study. Spine 
$1992 ; 17: 528-40$

28. Hashimoto T, Kaneda K, Abumi K. Relationship Between Traumatic Spinal Canal Stenosis and Neurologic Deficits in Thoracolumbar Burst Fractures. Spine $1988 ; 13: 1268-72$.

29. Boerger TO, Limb D, Dickson RA. Does 'Canal Clearance' Affect Neurological Outcome After Thoracolumbar Burst Fractures? J Bone Joint Surg Br 2000;82:629-35.

30. Kim NH, Lee HM, Chun IM. Neurologic Injury and Recovery in Patients With Burst Fracture of the Thoracolumbar Spine. Spine 1999;24:290-3.

31. Dickson JH, Harrington PR, Erwin WD. Results of Reduction and Stabilization of the Severely Fractured Thoracic and Lumbar Spine. J Bone Joint Surg Am 1978;60:799-805.

32. Burke DC, Murray DD. The Management of Thoracic and Thoraco-Lumbar Injuries of the Spine With Neurological Involvement. J Bone Joint Surg Br 1976;58:72-8.

33. Dai LY. Remodeling of the Spinal Canal After Thoracolumbar Burst Fractures Clin Orthop 2001;382:119-23.

34. de Klerk LW, Fontijne WP, Stijnen T, Braakman R, Tanghe HL, van Linge B Spontaneous Remodeling of the Spinal Canal After Conservative Management of Thoracolumbar Burst Fractures. Spine 1998;23:1057-60.

35. Karlsson MK, Hasserius R, Sundgren P, Redlund-Johnell I, Ohlin A. Remodeling of the Spinal Canal Deformed by Trauma. J Spinal Disord 1997;10:157-61.

36. Kuner EH, Schlickewei W, Kuner A, Hauser U. Restoration of the Spinal Canal by the Internal Fixator and Remodeling. Eur Spine .J 1997;6:417-22.

37. Yazici M, Atilla B, Tepe S, Calisir A. Spinal Canal Remodeling in Burst Fractures of the Thoracolumbar Spine: a Computerized Tomographic Comparison Between Operative and Nonoperative Treatment. J Spinal Disord 1996;9:409-13.

38. Johnsson R, Herrli, K, Hagglun, G, Stromqvist B. Spinal Canal Remodeling After Thoracolumbar Fractures With Intraspinal Bone Fragments. 17 Cases Followed 1-4 Years. Acta Orthop Scand 1991;62:125-7.

39. Fidler MW. Remodelling of the Spinal Canal After Burst Fracture. A Prospective Study of Two Cases. J Bone Joint Surg Br 1988;70:730-2.

40. Wessberg P, Wang Y, Irstam L, Nordwall A. The Effect of Surgery and Remodelling on Spinal Canal Measurements After Thoracolumbar Burst Fractures Eur Spine J 2001;10:55-63.

41. Dai L, Jia L, Zhao D, Xu Y. [Remodelling of the Spinal Canal After Thoracolumbar Burst Fractures: Significance of Nonoperative Management]. Zhonghua Wai Ke.Za Zhi 2000;38:610-2.

42. Mohanty SP, Venkatram N. Does Neurological Recovery in Thoracolumbar and Lumbar Burst Fractures Depend on the Extent of Canal Compromise? Spinal Cord 2002;40:295-9

43. Kraemer WJ, Schemitsch EH, Lever J, McBroom RJ, McKee MD, Waddell JP. Functional Outcome of Thoracolumbar Burst Fractures Without Neurological Deficit. J Orthop Trauma 1996;10:541-4.

44. Weinstein JN, Collalto P, Lehmann TR. Long-Term Follow-Up of Nonoperatively Treated Thoracolumbar Spine Fractures. J Orthop Trauma 1987;1:152-9.

45. Weinstein JN, Collalto P, Lehmann TR. Thoracolumbar "Burst" Fractures Treated Conservatively: a Long-Term Follow-Up. Spine 1988;13:33-8.

46. Wood K, Buttermann G, Mehbod A, Garvey T, Jhanjee R, Sechriest V, et al. Operative Compared With Nonoperative Treatment of a Thoracolumbar Burst Fracture Without Neurological Deficit. A Prospective, Randomized Study. J Bone Joint Surg Am 2003;85A:773-81.

47. Shen W.J, Liu T.J, Shen YS. Nonoperative Treatment Versus Posterior Fixation for Thoracolumbar Junction Burst Fractures Without Neurologic Deficit. Spine 2001;26:1038-45.

48. Tropiano P, Huang RC, Louis CA, Poitout DG, Louis RP. Functional and Radiographic Outcome of Thoracolumbar and Lumbar Burst Fractures Managed by Closed Orthopaedic Reduction and Casting. Spine 2003;28:2459-65.

49. Shen W.J, Shen YS. Nonsurgical Treatment of Three-Column Thoracolumba Junction Burst Fractures Without Neurologic Deficit. Spine 1999;24:412-5.

50. Chow GH, Nelson B.J, Gebhard .JS, Brugman .JL, Brown CW, Donaldson DH. Functional Outcome of Thoracolumbar Burst Fractures Managed With Hyperextension Casting or Bracing and Early Mobilization. Spine 1996;21:2170-
5.

51. Knight RQ, Stornelli DP, Chan DP, Devanny JR, Jackson KV. Comparison of Operative Versus Nonoperative Treatment of Lumbar Burst Fractures. Clin Orthop $1993 ; 293: 112-21$

52. Chipman JG, Deuser WE, Beilman GJ. Early Surgery for Thoracolumbar Spine Injuries Decreases Complications. J Trauma 2004;56:52-7.

53. Dai LY, Yao WF, Cui YM, Zhou Q. Thoracolumbar Fractures in Patients With Multiple Injuries: Diagnosis and Treatment-a Review of 147 Cases. J Trauma 2004;56:34855 .

54. Sarmiento A, McKellop HA, Llinas A, Park SH, Lu B, Stetson W, et al. Effect of Loading and Fracture Motions on Diaphyseal Tibial Fractures. J Orthop Res 1996;14:80-4.

55. McNamara M.J, Stephens GC, Spengler DM. Transpedicular Short-Segment Fusions for Treatment of Lumbar Burst Fractures. J Spinal Disord 1992;5:183-

56. Kaneda K, Abumi K, Fujiya M. Burst Fractures With Neurologic Deficits of the Thoracolumbar-Lumbar Spine. Results of Anterior Decompression and Stabilization With Anterior Instrumentation. Spine 1984;9:788-95.

57. Oda I, Cunningham BW, Lee GA, Abumi K, Kaneda K, McAfee PC. Biomechanical Properties of Anterior Thoracolumbar Multisegmental Fixation: an Analysis of Construct Stiffness and Screw-Rod Strain. Spine 2000;25:2303-11.

58. MeLain RF, Sparling E, Benson DR. Early Failure of Short-Segment Pedicle Instrumentation for Thoracolumbar Fractures. A Preliminary Report. J Bone Joint Surg Am 1993;75:162-7.

59. Holt BT, McCormack T, Gaines RW. Short Segment Fusion-Anterior or Posterior Approach? The Load-Sharing Classification of Spine Fractures. Spine $1993 ; 7: 227-85$.

60. Malcolm BW, Bradford DS, Winter RB, Chou SN. Post-Traumatic Kyphosis. A Review of Forty-Eight Surgically Treated Patients. J Bone Joint Surg Am $1981 ; 63: 891-9$

61. Viale GL, Silvestro C, Francaviglia N, Carta F, Bragazzi R, Bernucei C, Maiello M. Transpedicular Decompression and Stabilization of Burst Fractures of the Lumbar Spine. Surg Neurol 1993;40:104-11.

62. Karaikovic EE, Kaneda K, Akbarnia BA. Kaneda instrumentation for spinal fracture. Bridwall, KH and DeWald, RL. The Textbook of Spinal Surgery. 2 edn. Lippincott-Raven; 1997. p. 1899-924.

63. Briem D, Lehmann W, Ruecker AH, Windolf J, Rueger JM, Linhart W. Factors Influencing the Quality of Life After Burst Fractures of the Thoracolumbar Transition. Arch Orthop Trauma Surg 2004;124:461-8.

64. Gurwitz GS, Dawson JM, MeNamara M.J, Federspiel CF, Spengler DM. Biomechanical Analysis of Three Surgical Approaches for Lumbar Burst Fracture Using Short-Segment Instrumentation. Spine 1993;18:977-82.

65. MeDonnell MF, Glassman SD, Dimar JR, Puno RM, Johnson JR. Perioperative Complications of Anterior Procedures on the Spine. J Bone Joint Surg Am 1996;78:839-47.

66. Kaneda K, Taneichi H, Abumi K, Hashimoto T, Satoh S, Fujiya M. Anterior Decompression and Stabilization With the Kaneda Device for Thoracolumbar Burst Fractures Associated With Neurological Deficits. J Bone Joint Surg Am 1997;79:69-83

67. Roberson JR, Whitesides TE .Jr. Surgical Reconstruction of Late Post-Traumatic Thoracolumbar Kyphosis. Spine 1985;10:307-12

68. Leferink V.J, Keizer H.J, Oosterhuis .JK, van der Sluis CK, ten Duis H.J. Functional Outcome in Patients With Thoracolumbar Burst Fractures Treated With Dorsal Instrumentation and Transpedicular Cancellous Bone Grafting. Eur Spine .J $2003 ; 12: 261-7$

69. Polly DW, Klemme WR, Shawen S. Management Options for the Treatment of Posttraumatic Thoracic Kyphosis. Semin Spine Surg 2000;12:110-6.

70. Been HD, Poolman RW, Ubags LH. Clinical Outcome and Radiographic Results After Surgical Treatment of Post-Traumatic Thoracolumbar Kyphosis Following Simple Type A Fractures. Eur Spine J 2004;13:101-7.

71. Denis F. Thoracolumbar spine trauma. Lonstein, Bradford, Winter, and Ogilvie. Moes's Textbook of Scoliosis and Other Spinal Deformites. 3rd ed. Philadelphia: WB Saunders; 1995. 